Jambura Jaurnal of Linguistics and Literature

Vol. I, No. I, Hal. 14 - 22, Juni 2020

https://ejurnal.ung.ac.id/index.php/ijll

\title{
CITRA WANITA DALAM NOVEL SI PARASIT LAJANG KARYA AYU UTAMI
}

\author{
Ayu Hidayanti Ali \\ Universitas Negeri Gorontalo \\ hidayanti.denai@icloud.com
}

\begin{abstract}
Abstrak
Membaca novel dengan tokoh perempuan di dalamnya bukanlah hal yang asing, namun bila ditilik, kedudukan tokoh perempuan dalam novel kadang tampil terbatas. Perilaku dan ucapannya terikat oleh tatanan sosial yang dibangun masyarakat. Citra wanita dalam novel kemudian terkesan sekadar melengkapi cerita agar terlihat lebih seimbang. Padahal, citra wanita dalam sebuah novel bila diulas akan berbeda-beda. Novel Si Parasit Lajang karya Ayu Utami adalah salah satu novel yang menjadikan perempuan sebagai tokoh utamanya. Tokoh "saya" menampilkan citra wanita saat ini yang sebagian kecil memandang seksualitas dan pernikahan bukan sebuah keharusan. Citra wanita yang menjadi fokus penelitian dalam novel Si Parasit Lajang karya Ayu Utami yaitu citra wanita dalam hubungannya dengan Tuhan dan hubungannya dengan manusia lain. Penelitian ini menggunakan metode deskriptif analitik. Berdasarkan hasil analisis diperoleh satu citra wanita yang berhubungan dengan tuhan yaitu citra wanita yang sadar akan kedudukannya sebagai manusia yang lemah, dan dalam hubungannya dengan manusia lain diperoleh citra wanita yang memegang prinsip, acuh tak acuh, ramah dan akrab, apa adanya, serta penyayang.

Kata kunci: Citra wanita, Novel Si Parasit Lajang karya Ayu Utami, Feminisme
\end{abstract}

\begin{abstract}
Reading novels with female characters in them is no stranger, but when judging, the position of female characters in novels sometimes appears limited. His behavior and speech are bound by the social order that society builds. The image of the woman in the novel then seems to merely complement the story to make it look more balanced. In fact, the image of women in a novel when reviewed will vary. The novel Si Parasit Lajang by Ayu Utami is one of the novels that makes women the main character. The figure "I" displays the image of women today who a minority views sexuality and marriage as not a necessity. The image of women which is the focus of research in the novel Si Parasit Lajang by Ayu Utami is the image of women in their relationship with God and their relationship with other humans. This research uses descriptive analytic method. Based on the analysis results obtained by an image of women associated with God that is the image of women who are aware of their position as weak human beings, and in relation to other human beings the image of women who hold the principle, indifferent, friendly and close, as is, and merciful.
\end{abstract}

Key words: Women's image, Novel Si Parasit Single by Ayu Utami, Feminism

\section{PENDAHULUAN}

Novel adalah salah satu genre karya sastra yang saat ini diminati masyarakat. Daya tarik masyarakat dalam membaca novel tidak terlepas dari faktor kemenarikan realitas kehidupan yang disuguhkan dalam bentuk cerita yang sangat dekat dengan 
kejadian dan seringkali ditemui dalam kehidupan sehari-hari. Ditambah pula dengan dukungan berupa panjang halaman yang tidak terbatas sehingga penulis dapat mengisahkan dengan lebih leluasa. Ini pula yang dijelaskan oleh Aziz dan Hasim (2010:7) bahwa novel adalah sebuah genre sastra yang memiliki bentuk utama prosa, dengan panjang yang kurang lebih bisa untuk mengisi satu atau dua volume kecil, yang menggambarkan kehidupan nyata dalam suatu plot yang cukup kompleks.

Realitas kehidupan yang dibahas dalam novel amat beragam. Mulai dari masalah religi, sosial, budaya, dan masalah gender. Gender adalah salah satu isu yang seringkali menjadi topik yang diangkat para sastrawan dalam karyanya. Di dalam Novel, masalah gender dibicarakan dari berbagai sudut pandang yang berbeda. Oleh karena itu, ketika seseorang membaca novel maka akan melahirkan sebuah kepekaan terhadap isu-isu di sekitarnya. Salah satunya adalah kepekaan terhadap masalah gender. Inilah yang menurut Aminuddin (1991:35) bahwa sikap sungguh-sungguh dalam menggauli karya sastra dapat menumbuhkan pengertian, penghargaan, kepekaan kritis, dan kepekaan perasaan yang baik terhadap karya sastra. kepekaankepekaan tersebut tidak menutup kemungkinan akan melahirkan rasa ingin tahu yang lebih jauh terhadap karya sastra itu sendiri, sehingga akan dilakukan kajian terhadap karya-karya sastra khususnya yang bertemakan feminis. Novel-novel feminis saat ini akan dengan mudah ditemui, sebab permasalahan soal gender ini sudah digaungkan oleh R.A Kartini dalam tulisannya yang terkenal Habis Gelap Terbitlah Terang. Membaca novel dengan tokoh perempuan bukanlah hal yang asing, namun bila ditilik kedudukan tokoh perempuan dalam novel kadang tampil terbatas. Perilaku dan ucapannya terikat oleh tatanan sosial yang dibangun masyarakat. Citra wanita dalam novel kemudian terkesan sekadar melengkapi cerita agar terlihat lebih seimbang.

Pola pikir dan perasaan perempuan adalah salah dua hal yang membuat Citra wanita dalam setiap novel ditampilkan secara berbeda-beda. Novel Si Parasit Lajang karya Ayu Utami termasuk salah satu novel yang menjadikan perempuan sebagai tokoh utamanya. Tokoh "saya" sebagai representatif sebagian perempuan saat ini yang memandang seksualitas dan pernikahan bukan sebuah keharusan. Tokoh "saya" menyebut dirinya sebagai Si Parasit Lajang, sebuah istilah yang awalnya dipopulerkan oleh seorang feminis Jepang. Pernikahan bagi "saya" adalah hal sakral dan agung, sehingga seharusnya tidak sembarang orang bisa untuk menikah. Novel ini juga menceritakan bagaimana keseharian "saya" yang menjumpai banyak hal. Mulai dari kebiasaan teman-temannya yang senang menonton blue film bahkan teman perempuannya juga. Soal pandangan orang-orang di sekitarnya mengenai pernikahan. Bahkan tokoh "saya" menceritakan bahwa dirinya telah berhubungan badan dengan pacarnya dan ketika putus, ia tidak menyesali hal itu, karena saat melakukan hal itu menurutnya suka sama suka. Sehingga tak ada yang dirugikan.

Novel Si Parasit Lajang adalah adalah novel bagian pertama dari trilogi, yang kedua yaitu Cerita Cinta Enrico, dan yang terakhir adalah Pengakuan Eks Parasit Lajang. Penulisnya memiliki nama lengkap Justina Ayu Utami. Ia lahir di Bogor, Jawa Barat 21 November 1968. Pengalaman hidup yang ditumpahkan oleh Ayu Utami dalam novel ini memiliki banyak keunikan dan bisa membuka cara pandang terhadap hal-hal kecil yang dijumpai dalam kehidupan sehari-hari. Inilah yang menurut 
Pujiharto (2012:19) menjadi pembeda pengarang dengan ilmuan, sejarawan, filsuf atau teolog. Seorang pengarang memandang pengalaman bukan semata-mata bersifat universifal, tetapi juga memiliki keunikan. Seorang pengarang berusaha memahami dan menggambarkan suatu pengalaman individual sembari melestarikan keunikan dan kehidupan.

Banyaknya penulis-penulis perempuan saat ini tidak lepas dari kenyataan bahwa pemikiran mengenai feminisme semakin subur di tengah-tengah masyarakat. Apalagi keberadaan feminisme sastra ini dapat mengidentifikasi seperti apa tokoh perempuan dalam sebuah novel digambarkan oleh penulisnya. Seperti yang diungkapkan Sugihastuti dan Suharto (2010:15) bahwa dasar penelitian feminisme sastra adalah upaya pemahaman kedudukan dan peran perempuan seperti tercermin dalam karya sastra. Tak jauh berbeda, Endraswara (2013:146) mengungkapkan dasar pemikiran dalam penelitian sastra berprespektif feminis adalah upaya pemahaman kedudukan dan peran perempuan seperti tercermin dalam karya sastra. Peran dan kedudukan perempuan tersebut akan menjadi sentral pembahasan penelitian sastra. Jika kedua pendapat di atas menitik beratkan pada kedudukan perempuan dalam karya sastra. Maka, Tuloli menjelaskan lebih terperinci lagi soal bagaimana harus melihat kajian wanita dalam kesuasteraan dari dua sisi. Konsep utama pendekatan feminis adalah masalah dimensi moral dan politik. Citra kritik feminis, yang terutama berkaitan dengan bagaimana karakter-karakter wanita diwakili dalam sastra, terutama dalam karya-karya yang ditulis oleh kaum pria. Lanjut, menurutnya kajian wanita dalam hubungannya dengan kesusasteraan dapat dilihat dari dua sisi. Sisi pertama, dari sisi karya sastra terdapat ketimpangan tentang kedudukan wanita. Elaine Showalter, mengemukakan bahwa sejumlah besar bentuk sastra dalam sejarah Amerika, tidak menyinggung satupun penulis wanita. Karenanya salah satu kegiatan awal para pengeritik sastra feminis adalah menggali, mengkaji, serta menilai karya penulispenulis wanita. Yang perlu dipertanyakan tolok ukur apa yang dipakai pengeritik sastra dahulu, sehingga kritikan mereka hanya pada penulis laki-laki. Sisi kedua, dari sisi teori pendekatan terhadap karya sastra. Teori ini akan menjadi suatu konteks yang dapat mendukung penulis wanita masa kini agar mereka mampu mengungkapkan pengalaman, perasaan, serta pikiran yang selama ini diredam (Tuloli, 2000:85-86). Dari ketiga pendapat tersebut dapat disimpulkan bahwa feminisme hadir untuk melihat seperti apa kedudukan dan peran perempuan dalam novel dan keberanian penulis wanita untuk menuliskan isi-isi pikiran yang berupa keresahan terhadap masalah yang dihadapi kaumnya.

Pikiran-pikiran bebas tokoh "saya" dan karakternya yang khas merupakan salah satu citra wanita yang dapat kita temui dalam novel Si Parasit Lajang. Citra itu sendiri menurut Sugihastuti (2002:45) adalah rupa atau dapat berupa gambaran yang dimiliki oleh orang, mengenai pribadi atau kesan mental (bayangan) visual yang ditimbulkan oleh sebuah kata, frase, atau kalimat yang merupakan unsur dasar yang khas pada prosa dan puisi. Ketika citra dipadankan dengan kata wanita, maka akan melahirkan sebuah pengertian yang baru. Menurut Sugihastuti (2002:7) Citra wanita adalah semua gambaran mental spiritual dan tingkah laku keseharian wanita (Indonesia) yang menunjukkan "wajah" dan cirri khas wanita sebagai makhluk 
individu dan sebagai makhluk sosial. Hal ini berarti bahwa citra wanita tidak akan terlepas dari sikap dan tingkah laku yang ditunjukkan dalam kehidupannya sehari-hari.

Dalam novel Si Parasit Lajang karya Ayu Utami, tokoh "saya" adalah tokoh utamanya. Bekerja sebagai seorang wartawan, membuat tokoh "saya" menjadi wanita dengan pikiran-pikiran kritis dan bergaya bebas. Citra wanita yang dipilih tokoh "saya" dalam novel Si Parasit Lajang banyak yang masih dianggap tabuh dalam masyarakat. Misalnya soal keperawanan dan pernikahan yang menurutnya tidak harus dipercaya dan dilakukan. Ayu Utami sendiri sebagai penulis merupakan seorang sastrawan yang sering menyuarakan pendapat kritisnya terkait gender. Kesetaraan dan perlakuan yang sama tanpa memandang jenis kelamin adalah salah satu yang diperjuangkan oleh para feminis. Hal ini seperti pendapat Humm (Wiyatmi, 2012:10) bahwa feminisme menggabungkan doktrin persamaan hak bagi perempuan yang menjadi gerakan yang terorganisasi untuk mencapai hak asasi perempuan, dengan sebuah ideologi transformasi sosial yang bertujuan untuk menciptakan dunia bagi perempuan. Selanjutnya, Humm menyatakan bahwa feminisme merupakan ideologi pembebasan perempuan dengan keyakinan bahwa perempuan mengalami ketidakadilan karena jenis kelaminnya. Dalam novel ini ideologi feminisme itu disampaikan oleh tokoh "saya".

Dari berbagai macam citra yang ditampilkan oleh tokoh "saya" yang sangat menarik menurut peneliti adalah soal hubungannya dengan Tuhan dan orang lain. Oleh karena itu, batasan penlitian ini hanya di dua citra wanita. yaitu hubungannya dengan Tuhan dan hubungannya dengan manusia lain. Berangkat dari batasan masalah tersebut, rumusan masalah yang diangkat oleh peneliti yaitu pertama, Bagaimana Citra wanita dalam hubungannya dengan tuhan pada novel Si Parasit Lajang Karya Ayu Utami? dan kedua, Bagaimana Citra wanita dalam hubungannya dengan manusia lain pada novel Si Parasit Lajang Karya Ayu Utami?. Berdasarkan rumusan masalah tersebut, tujuan penelitian ini juga terbagi atas dua, yaitu untuk mendeskripsikan Citra wanita dalam hubungannya dengan Tuhan dan Citra wanita dalam hubungannya dengan manusia lain pada novel Si Parasit Lajang Karya Ayu Utami.

Citra wanita dalam novel Si Parasit Lajang Karya Ayu Utami bukan pertama kali diteliti. Beberapa penelitian telah dilakukan sebelumnya, misalnya penelitian yang dilakukan oleh Masriah tahun 2015 dengan judul penelitian Sikap Radikal Tokoh Perempuan dalam Si Parasit Lajang Karya Ayu Utami. Penelitian ini menganalisis tentang: (1) sikap radikal tokoh perempuan yang ditunjukkan yakni tidak menikah, melepas keperawanan, kebebasan berekspresi secara seksual, tidak ingin hamil, melawan budaya patriarki, dan menentang agama, (2) faktor-faktor yang menyebabkan tokoh perempuan memilih tidak menikah meliputi, tidak merasa perlu menikah, tidak peduli masyarakat terlalu mengagungan pernikahan, tidak berbakat, kepadatan penduduk, seks tidak identik dengan pernikahan, sudah terlalu asik melajang, dan tidak mudah percaya.

Penelitian di atas dengan penelitian ini sama-sama meneliti novel Si Parasit Lajang karya Ayu Utami. Perbedaannya terletak pada fokus masalah yang diteliti. Bila penelitian ini fokus pada citra wanita, maka penelitian kedua fokus pada sikap radikal tokoh perempuan dalam novel Si Parasit Lajang karya Ayu Utami. 


\section{METODE}

Metode yang digunakan dalam penelitian ini adalah metode deskriptif analitik. Menurut Ratna (2010:53) metode deskriptif analitik dilakukan dengan cara mendeskripsikan fakta-fakta yang kemudian disusul dengan analisis. Jenis penelitian ini adalah penelitian kualitatif. Sumber penelitian ini adalah novel Si Parasit Lajang Karya Aуи Utami yang diterbitkan oleh Kepustakaan Gramedia, Jakarta pada tahun 2013 dengan jumlah halaman 201 halaman. Dalam menganalisis, berikut langkahlangkah yang dilakukan oleh peneliti, yakni: (1)mengumpulkan data yang sesuai dengan rumusan masalah; (2)mengidentifikasi dan mengelompokkan data yang diperoleh termasuk dalam kategori citra wanita seperti apa; (3)menganalisis data yang sudah siap; (4)mendeskripsikan hasil analisis; (5)menyimpulkan citra wanita dalam novel Si parasit Lajang Karya Ayu Utami.

\section{HASIL DAN PEMBAHASAN}

Citra wanita yang diperlihatkan oleh tokoh "saya" dalam novel Si parasit Lajang Karya Ayu Utami adalah citra seorang perempuan yang berani untuk bicara tentang isi kepalanya yang digeluti keresahan atas nasib kaumnya yang diikat berbagai macam tradisi. Sebagai seorang perempuan, tokoh "saya" menggambarkan hubungannya dengan Tuhan dengan cara yang berbeda. Berikut kutipan yang menunjukkan bagaimana tokoh "saya" melempar sebuah pertanyaan yang mungkin akan melahirkan penafsiran yang berbeda-beda, bahkan bisa jadi memunculkan kontroversi.

Saya teringat seorang teman. Dia pria, sudah menikah, dan punya pacar lagi. Si pacar mau bersetubuh dengan dia tetapi dia hanya mau jika mereka menikah. Pacar itu jadi istri keduanya. Saya bilang, "kenapa tidak berzinah saja?" Ia jawab, "nanti tuhan menangis." Saya katakan lagi, "kenapa kamu memilih menyakiti istrimu, pihak yang lemah, ketimbang menyakiti Tuhan yang sudah begitu kuat? (Utami, 2013:177).

Citra wanita terkait hubungan dengan Tuhan dalam kutipan di atas adalah citra wanita yang sadar akan kedudukannya sebagai manusia yang lemah. Walaupun tokoh "saya" adalah seorang feminis, tetapi ia sadar bahwa perempuan sebagai seorang hamba, adalah manusia yang lemah. Perasaan ingin disetiakan oleh pasangan pasti menjadi harapan setiap perempuan. Oleh karena itu, perkataan tokoh "pria" yang memutuskan menikah lagi membuat tokoh "saya" geram.

Kutipan di atas juga membuktikan bahwa saya adalah orang yang memiliki hubungan baik dengan Tuhan. Sebagaimana hubungan seorang hamba dengan penciptanya. Meskipun kalimat terakhir pada kutipan di atas terkesan seolah-olah tokoh "saya" menganggap bahwa seharusnya tidak masalah dengan zina karena hanya akan menyakiti Tuhan yang lebih kuat, tetapi sebenarnya tokoh "saya" sedang menyindir pria yang menjadi lawan bicaranya yang membawa-bawa Tuhan dalam urusan hawa nafsu.

Kalimat "kenapa kamu memilih menyakiti istrimu, pihak yang lemah" juga mencerminkan bahwa citra wanita yang ditampilkan tokoh saya adalah jujur. Sebagai 
seorang hamba, tokoh "saya" percaya bahwa Tuhan punya kekuatan yang lebih dibanding manusia. Seorang wanita yang sudah menjadi istri akan sangat terluka untuk menerima kehadiran orang ketiga dalam hubungan rumah tangganya. Untuk seorang wanita dengan pemikiran liberalis yang kental dan juga feminis sejati, tokoh "saya" tetap jujur

Dalam novel Si Parasit Lajang ini, tokoh "saya" memang kurang setuju terkait urusan poligami. Ketidaksetujuannya ini dipicu ketidakmampuannya sebagai perempuan untuk menerima kenyataan bahwa suami harus menikah lagi. Oleh karena itu, ketika ia mendengar tokoh "Pria" ini bercerita soal pernikahan keduanya yang pastinya akan membuat hati istri pertama remuk redam, maka tokoh "saya" menjadi sinis dengan melontarkan kalimat "kenapa kamu memilih menyakiti istrimu, pihak yang lemah, ketimbang menyakiti Tuhan yang sudah begitu kuat?". Dalam pemahaman tokoh "saya", seharusnya suami istri saling setia dan menjaga perasaan. Tidak semena-mena berbuat poligami tanpa mempertimbangkan perasaan istri pertama. Kalau bisa untuk berusaha setia, mengapa harus memikirkan untuk menikah lagi.

Selain hubungan dengan Tuhan, tokoh "saya" dalam novel Si Parasit Lajang karya Ayu Utami menampilkan citranya sebagai wanita dalam hubungannya dengan orang lain. Berikut kutipannya.

Ya, saya punya trauma. Bukan pada lelaki, sebagaimana yang dikira banyak orang, melainkan pada sesama perempuan yang tidak sadar bahwa mereka tunduk dan melanggengkan nilai-nilai patriarki. Saya punya dua bibi pemuja perkawinan. Salah satunya begitu mengagungkan persuntingan sehingga jika saya menikah, ia takkan menyapa saya dalam suratnya dengan nama saya, melainkan sebagai nyonya suami. Tapi mereka sendiri tidak menikah. Bukan karena tak mau, melainkan karena tak dapat. (Utami, 2013:xvi)

Tokoh "saya" adalah tipikal perempuan yang ingin bebas, tak memikirkan masalah pernikahan, karena ia merasa trauma dengan kejadian kedua bibinya yang sangat memuja pernikahan dan justru mereka tidak menikah. Perbedaan prinsip tokoh "saya" dan kedua bibinya telah memunculkan citra wanita yang berpegang teguh pada prinsip Tokoh "saya" menyebutkan di awal kalimat bahwa ia termasuk perempuan yang tidak ingin tunduk dengan nilai-nilai patriarki. Ia memegang prinsip itu dengan tidak menjadi seperti kedua bibinya yang begitu mengagung-agungkan persuntingan/pernikahan. Tokoh "saya" juga menampilkan rasa miris di akhir kutipan dengan menjelaskan bahwa kedua bibinya yang sangat memuja pernikahan itu justru belum menikah karena belum bertemu dengan jodohnya.

Selanjutnya, citra wanita dalam hubungannya dengan manusia lain ditunjukkan oleh tokoh "saya" pada saat ia bertemu guru-guru di sekolahnya.

"Saya juga punya guru-guru SD dan SMP yang memenuhi segala stereotipe tentang "perawan tua": perempuan "tidak laku" yang dengki. Mereka mengidealkan perkawinan, tapi mereka sendiri tidak mendapatkan suami. Mereka adalah guru-guru paling killer di sekolah. Mereka menghukum dengan berlebihan. Mereka membenci murid-murid yang cantik. Syukurlah saya cenderung tomboy waktu sekolah, sehingga mereka baik pada saya. Dengan 
demikian saya punya simpati baik pada si guru maupun pada korbannya. Sembari, tetap merasakan ketidakadilan”. (Utami, 2013:xvi)

Citra wanita acuh tak acuh ditampilkan oleh tokoh "saya" pada kutipan di atas. Sebagai seorang wanita, hubungannya dengan guru-guru sekolah baik-baik saja, karena guru-guru killer tersebut hanya membenci kepada teman-temannya yang cantik. Tokoh "saya" sendiri adalah seorang wanita tomboy yang berusaha simpatik kepada guru-gurunya yang tidak menikah sehingga sering dijuluki "perawan tua", namun rasa simpatiknya tersebut tidak bisa menutupi rasa ketidakadilan atas perilaku guru-gurunya yang mnghukum teman-temannya cantik secara berlebihan. Tokoh "saya" acuh dengan keadaan teman-temannya, namun di sisi lain ia merasa tak acuh dikarenakan ia bukan termasuk dalam kategori wanita yang cantik sehingga ia beruntung diperlakukan baik oleh guru-gurunya.

Tokoh "saya" sempat kehilangan pekerjaan namun tak lama setelah itu ia mendapat pekerjaan baru di Jurnal Kebudayaan. Tokoh "saya" memang sangat tertarik dengan dunia menulis. Di tempat baru inilah akhirnya ia bertemu dengan seorang lelaki bernama Sahal yang kemudian menjadi teman akrabnya. Berikut kutipannya:

"Kehilangan pekerjaan, saya pun mendarat di jurnal kebudayaan kalam itu. Jadilah saya kolega kerja sahal. Ketika itulah baru saya bisa ingat siapa dia. Dia selalu membuat kami tertawa di ruang rapat. Dia lebih suka ke kantor menjelang tengah malam, sebab pada jam itu pemimpin redaksi jurnal pastilah sudah pulang. Dan dia meninggalkan kompor kantor menyala dengan teko yang mulai gosong karena airnya habis menguap. Dia membuat kami geli dan degdegan sekaligus. Terutama sejak insiden cerek hangus itu saya tidak akan pernah lupa dia. Sesuatu padanya membuat kita tidak bisa marah. Itulah Sahal. Orang Jepara kedua yang saya tahu, setelah Ibu Kartini”. (Utami, 2013:5)

Kutipan di atas menggambarkan tentang hubungan pertemanan yang dijalin tokoh "Sahal" dan tokoh "Saya". Keakraban mereka dimulai karena sama-sama bekerja di jurnal kebudayaan. "Saya" termasuk tipikal orang yang tidak mudah mengingat seseorang, namun karena karakter "Sahal" yang lucu, tokoh "Saya" dengan mudah mengenal "Sahal" sebagai pemuda yang berasal dari Jepara.

Citra wanita yang ramah dan akrab dimunculkan oleh tokoh "saya" pada kutipan di atas. Meskipun pemikirannya kritis dan feminis, tokoh "saya" bukan berarti tidak lagi menjalin pertemanan dengan laki-laki. Ia justru banyak berdebat dan bertukar pikiran dengan mereka. Sampai akhirnya ia berkenalan dengan "Sahal", seorang lelaki kelahiran Jepara yang tingkahnya selalu membuat tertawa.

Selain "Sahal", tokoh "saya" juga memiliki seorang teman. Namanya Cynta. Dari temannya inilah tokoh "saya" menonton sebuah film biru berjudul Tarzan.

"Cynta ternyata tidak hanya spontan dalam menyatakan pendapat politik. Dari dialah saya akhirnya menonton film yang seru itu: Tarzan. Oh, film biru tentu!". (Utami, 2013:28)

Kutipan di atas menggambarkan tentang hubungan "Saya" dengan seorang gadis bernama "Cynta". "Cynta" merupakan gadis yang spontan dan juga bahkan blak- 
blakkan. Sebagai wanita, tokoh "saya" menunjukkan citranya yang apa-adanya. Dengan menonton film biru bersama teman wanitanya, tokoh "saya" ingin mematahkan stereotip bahwa wanita tak harus malu untuk menonton film yang biasanya lebih banyak ditonton oleh lelaki.

Tokoh "saya" ingin menunjukkan citra wanita yang selalu tunduk dengan norma sosial yang cenderung patriarki itu tidak berlaku padanya. Ia adalah wanita yang bebas dan bisa mempertanggungjawabkan apa yang telah dipilihnya. Menonton film biru bukan hal yang salah selama tidak menjadikannya sebagai hobi. Tokoh "saya" hanya ingin menjadi dirinya sendiri. itulah juga yang membuatnya sadar bahwa ia sangat berbeda dengan ibunya. Berikut kutipannya:

"Ibu saya adalah makhluk terindah. Ia begitu beda dari saya. Ia tak pernah berganti pacar. Saya ganti pacar lima kali (di luar yang tak terhitung pacar). Ia percaya bahwa menikah adalah jalan hidup terbaik manusia, kecuali jika orang menjadi suster atau biarawan." (Utami, 2013:78)

Meskipun tokoh "saya" menjalani hidup berbeda dari ibunya, ia tetap menunjukkan bahwa ia adalah wanita dengan citra yang sangat baik, yaitu mencintai dan menghargai ibunya. Hal ini dapat dilihat pada kalimat "Ibu saya adalah makhluk terindah". Sebagai seorang anak, ia mengagumi ibunya yang secara nyata berbeda sudut pandang dalam urusan gender dan nilai-nilai patriarki. Baginya urusan pernikahan yang tidak dia percayai tidak lantas membuat dia harus juga membenci ibunya karena turut melanggengkan nilai-nilai patriarki yang dipuja oleh masyarakat. Ia hanya tidak ingin menikah. Itu saja. Kalau orang lain ingin menikah, itu urusannya. Hanya saja, baginya seharusnya tak sembarang orang menikah, karena pernikahan itu agung dan sakral. Maka tidak cocok untuk orang-orang yang pantas, dan dia merasa dirinya juga tidak pantas.

Citra yang ditunjukkan oleh tokoh "saya" dalam novel Si Parasit Lajang karya Ayu Utami adalah bentuk ketidakpuasan dan keresahan dari seorang wanita atas kondisi di sekitarnya. Bahkan baginya undang-undang pernikahan pun tidak sadar jender. Misalnya, dalam pernikahan lelaki adalah kepala keluarga. Akibatnya, istri jadi bayar pajak lebih besar dari suami karena penghasilannya dianggap pendapatan tambahan. Sebagai seorang wanita, Ayu Utami berusaha memperjuangkan kesetaraan gender yang selama ini masih tabuh bagi sebagian orang. Lewat novel Si Parasit Lajang dan tokoh "saya" ia menceritakan segala kenyataan tentang bias gender yang didapatinya. Mulai dari orang-orang yang mempermasalahkan bentuk tubuh dan kulit perempuan. Padahal hal itu kadang justru tidak berlaku untuk lelaki.

\section{PENUTUP}

Novel Si Parasit Lajang yang ditulis oleh Ayu Utami adalah novel yang berusaha untuk menyodorkan kepada pembaca tentang pendapat dan pola pikir perempuan di rezim Reformasi. Wanita yang bebas berekspresi dan melakukan apa yang dilakukan oleh lelaki, namun sering berbenturan dengan kebudayaan patriarki yang terlalu menyanjung kesuperheroan seorang lelaki. Sehingga hal ini seringkali memicu ketidakadilan kepada perempuan. Tokoh "saya" dalam novel Si Parasit 
Lajang karya Ayu Utami menggambarkan hubungannya dengan Tuhan dengan cara yang berbeda. Bila kadang-kadang manusia lain akan mengutamakan Tuhan, maka tokoh "saya" justru membela kaumnya ketika seorang kawan prianya yang sudah menikah ternyata menikah lagi dengan pacarnya dan tega menyakiti hati istrinya. Begitu pula hubungannya dengan orang lain. Pada bagian ini, tokoh "saya" menceritakan bagaiamana orang-orang yang dikenalnya sangat mengagung-agungkan pernikahan, namun ada yang justru tidak menikah seperti bibinya, ada yang kemudian menjadi pembenci terhadap murid-murid yang cantik seperti guru-guru SD dan SMP nya, dan yang terakhir yaitu ibunya sendiri yang begitu mengagungkan pernikahan dan tak pernah berganti pacar seperti dirinya.

Tokoh "saya" juga ingin menunjukkan bahwa perempuan harus berani apa adanya. Berani berbuat hal-hal yang mungkin selama ini tabu untuk dilakukan, misalnya menonton film biru, namun hal ini tidak untuk dijadikan hobi dan tentu bukan untuk dilakukan oleh anak-anak dalam usia bangku sekolah. Tokoh "saya" hanya ingin memperjuangkan kesetaraan gender yang selama ini selalu tertutupi oleh norma dan aturan-aturan sosial di tengah masyarakat. Padahal, menurutnya perempuan juga harus independen. Berani menyuarakan isi kepala tanpa harus takut dikenakan label feminis.

\section{DAFTAR PUSTAKA}

Aminuddin. 1991. Pengantar Apresiasi Karya Sastra. Bandung: Sinar Baru.

Aziez, Furqonul dkk. 2010. Menganalisis Fiksi (Sebuah Pengantar). Bogor: Ghalia Indonesia.

Endraswara, Suwardi. 2013. Metodologi Penelitian Sastra: Epistemologi, model, teori, dan Aplikasi. Jakarta: CAPS.

Pujiharto. 2012. Pengantar Teori Fiksi. Yogyakarta: Ombak.

Ratna, Nyoman Kutha. 2010. Teori, Metode dan Teknik Penelitian Sastra. Yogyakarta: Pustaka Pelajar.

Suharto dan Sugihastuti. 2010. Kritik Sastra Feminis. Yogyakarta: Pustaka Pelajar.

Tuloli, Nani. 2000. Kajian Sastra. Gorontalo: BMT Nurul Jannah.

Utami, Ayu. 2013. Si Parasit Lajang. Jakarta: KPG.

Wiyatmi. 2012. Kritik Sastra Feminis: Teori dan Aplikasinya Dalam Sastra Indonesia. Yogyakarta: Ombak. 